\title{
ADDRESSING COGNITIVE CHALLENGES IN DESIGN - A REVIEW ON EXISTING APPROACHES
}

\author{
Ning, Weining; Goodman-Deane, Joy; Clarkson, P.John \\ Engineering Design Centre, Department of Engineering, University of Cambridge
}

\begin{abstract}
Insufficient design often causes challenges to users on a cognitive level, hindering them from interacting with products smoothly. There is a lack of effective design tools and supporting materials that can help designers to understand human cognition and how it affects the way that users experience and use products and services. This paper aims to identify current approaches that can be applied to address this issue, and to examine their strengths and weaknesses. This helps to identify future directions for developing and improving cognitive design supports. A literature review was conducted of research publications in the fields of both design and cognition. Four key approaches are identified: cognitive design principles/guidelines, the demand-capability approach, cognitive walkthrough and cognitive modelling. Their strengths and weaknesses are analyzed from a design standpoint. The paper also analyses the underlying causes of the insufficient uptake of cognitive design approaches by designers.
\end{abstract}

Keywords: Cognitive challenge, Inclusive design, User centred design, Design methods

\section{Contact:}

Ning, Weining

University of Cambridge

Department of Engineering

United Kingdom

wn228@cam.ac.uk

Cite this article: Ning, W., Goodman-Deane, J., Clarkson, P.J. (2019) 'Addressing Cognitive Challenges in Design - A Review on Existing Approaches', in Proceedings of the 22nd International Conference on Engineering Design (ICED19), Delft, The Netherlands, 5-8 August 2019. DOI:10.1017/dsi.2019.284 


\section{INTRODUCTION}

Users' cognitive function plays a big part in using interactive products. The mental processes and actions involved in people's cognition have a huge impact on their performance with a product. For example, they affect how people learn to operate a product, understand the information displayed by a product interface and plan actions in product interaction (Tenneti et al., 2013). In order to deliver usable products, designers should have a deep understanding of the cognitive characteristics of intended users so as to mitigate potential cognitive barriers.

However, the knowledge concerning people's cognition is interdisciplinary in nature (Thagard, 2017), indicating that it is difficult for an individual to grasp. In practice, designers tend to rely on their acquired experience, intuition and common sense to make decisions (Altay, 2017). As a result, cognitive challenges in product interaction are common among everyday products.

Cognitive challenges in a design can be understood as operational difficulties that primarily place demands on users' cognition rather than on their sensory or motor capabilities. For example, in the interface in Figure 1 the elements are relatively clear to read (when viewed at full size) and the buttons and dial can be manipulated easily. However, it is difficult for a user to form a sensible operational sequence for a specific goal.

Human cognition is highly complex, and the cognitive interface of a product is often a big challenge for designers. This is exacerbated by the desirability of accommodating an extremely wide range of functions and users (Peacock and Resnick, 2011). There remains a need to develop design supports to help designers to obtain a better understanding of users' cognition and subsequently equip them to address cognitive challenges in design.

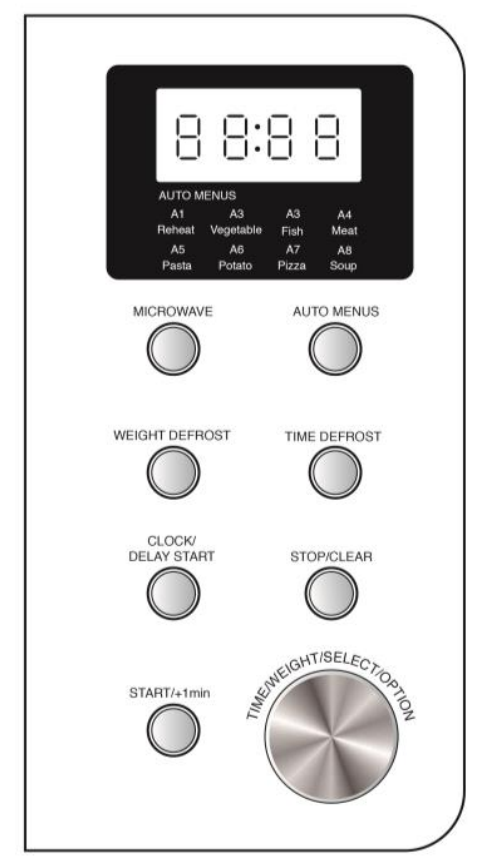

Figure 1. A microwave interface which induces cognitive challenges

In this study, a literature review was conducted to identify the current approaches that can be used to address cognitive challenges in design and the factors which may inhibit their uptake by designers. The review examines research publications from both design and cognition-related fields where cognitive issues were addressed within a human-product interaction context.

It can be reasonably argued that there is a wide selection of Human-Centered Design (HCD) approaches which can be applied in addressing cognitive challenges. However, typical HCD methods such as user testing are expensive (Darses and Wolff, 2006). When implementing these methods, the time spent in recruiting, screening, scheduling and conducting tests can create a bottleneck for product development, especially for products with frequent release and rapid iteration (Shankar et al., 2015). Other methods such as heuristic and expert evaluation may involve personal biases towards specific design features, and 'it is often hard to set aside one's expertise and assume the role of the user' 
(Maguire, 2001). As a result, this review focuses on approaches that are specifically used to address cognitive challenges, aiming to understand why they are not widely adopted by designers. This can help to direct further efforts to improve designers' understanding of users' cognitive behaviors.

\section{METHODOLOGY}

The research concerning human cognition is wide-ranging and the fields involved grew and developed concurrently with overlapping thematic areas. Gersh et al. (2005) identified cognitive science, cognitive psychology, cognitive engineering, human factors/ergonomics, systems engineering and human-computer interaction (HCI) as the key areas involved in understanding human cognition within a technical system. These identified areas served as an appropriate starting point for the literature exploration. In addition to these areas, particular attention was also paid to design research publications so as to investigate how cognitive challenges are addressed in the field of design itself.

Figure 2 shows the literature search and filtering process. One stream of work involved examining available methods and tools in each cognitive research area. Further work then searched for the application of these methods and tools in human-product interaction. In order to ensure the inclusion of as wide a range of publications as possible, 'product' was considered to refer to any designed system that involved human operators. During this step, methods or tools were excluded if they showed a low degree of feasibility or practicality for the design of everyday products. For instance, functional magnetic resonance imaging (fMRI) was used for measuring cognition activities but rarely showed applications in enhancing design. Therefore, it was excluded from the follow-up analysis.

The retrieved and filtered research publications in both cognitive and design fields were subsequently combined to form a collection of methods and tools that are used to tackle cognitive issues in product design. Those methods and tools were then classified into more general 'approaches' with similar features. Four main approaches were identified and their strengths and weaknesses were then analysed.

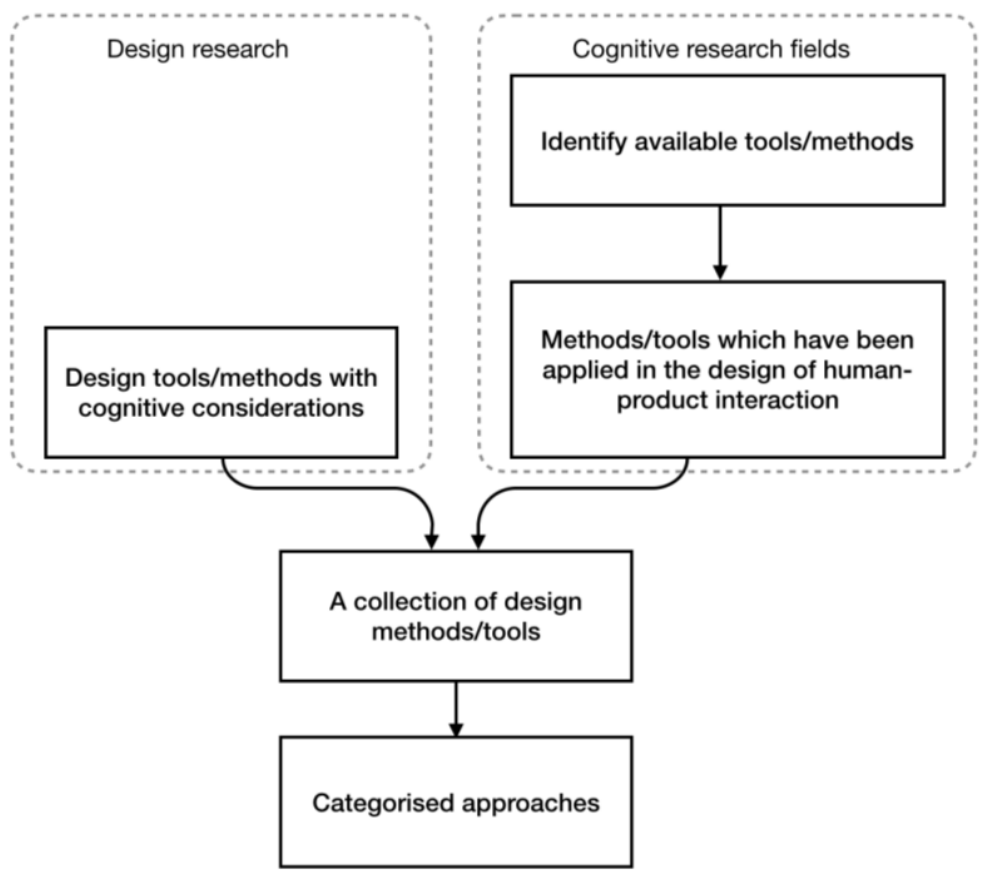

Figure 2. The process of selecting and synthesizing approaches

\section{KEY APPROACHES TO ADDRESS COGNITIVE CHALLENGES IN DESIGN}

Four commonly used approaches were selected within the scope of the consulted publications. Together, these approaches cover the whole cycle of the design process. Cognitive design principles and guidelines are mostly used in the initial stages of the design process to guide the formation of design, while cognitive walkthrough and cognitive models are more advantageous in evaluation. The 
capability-demand approach can be reasonably argued to stand in the middle as it provides insights in early stages as well as methods to assess the quality of a design.

\subsection{Cognitive design principles and guidelines}

Design principles and guidelines are widely used by designers (Nickpour and Dong, 2015). Part of the reason for this may be that guidelines summarise a lot of knowledge and experience into a form that is easy to refer to. In addition, designers often rely heavily on personal experience in design decision making. When they do not have enough previous experience themselves on a specific design topic, they may instead like to refer to other designers' successful experiences. Guidelines can be considered to be one way to encapsulate such experiences (Abascal and Nicolle, 2005).

There are various cognitive design guidelines based on systematic analysis of the characteristics of human cognition and related functions. For example, Johnson (2013) proposed a set of guidelines in attempt to address design issues concerning users' vision, reading, learning etc. Cognitive design principles tend to be presented in a more simplified format. For instance, Kalyuga et al. (2010) proposed a set of guidelines to minimise users' cognitive load, including:

1. The direct initial instruction principle (provide worked-out examples);

2. The expertise principle (adapt instruction to cater for different levels of learner expertise);

3. The small size of knowledge change principle (avoid providing too much information too quickly).

In the example of a microwave in Figure 1, applying these principles could result in displaying an example of how to operate the microwave on the interface itself (principle 1), and reducing the number of buttons or grouping buttons which represent similar functions (principle 3).

Similar guidelines and principles can be found in the Metaphor of Human Thinking (Frøkjær and Hornbæk, 2008) and the User Interface Design Principles for Interaction Design (Blair-Early and Zender, 2008).

Employing design guidelines or principles provides designers with a relatively fast and easy way to develop design. The apparent simplicity of guidelines and principles, however, also brings about problems when putting them into practice (Bastien and Scapin, 1992, 1995):

- Which to choose - There are numerous guidelines and principles available to designers, but there are no instructions to assist them in finding one that perfectly matches their needs;

- How to establish priorities - When several rules apply or conflict arises, designers have to balance one against another;

- How to translate guidelines into design rules - Guidelines are often vague and hard to test, making it difficult for designers to understand what is required of them, convert them into design rules and implement those requirements in practice.

Putting design guidelines and principles into practice can be even more problematic within the realm of cognition. Firstly, cognitive psychology is an area with an especially messy and at times contradictory body of literature. There is no standard reference for designers to follow. Moreover, designers rarely have backgrounds in cognitive psychology and this makes the existing guidelines and principles difficult for them to implement properly (Johnson, 2013). Lastly, cognitive design guidelines are not always packaged in the most usable way, making it difficult for designers to use them (Zaphiris et al., 2006).

\subsection{The capability-demand approach}

The capability-demand approach provides a more pragmatic way of understanding the interplay between users' cognition and product features, because it directly relates the two within a product interaction context. According to this approach, products place demands on their users' capabilities. A user whose capability does not meet a demand will not be able to use the product effectively and can be considered to be 'excluded' from its use (Clarkson et al., 2015).

This approach originates from the field of inclusive design. Inclusive design is 'the design of mainstream products and/or services that are accessible to, and usable by, people with the widest range of abilities within the widest range of situations without the need for special adaptation or design' (BSI, 2005). Inclusive design employs commonly-used HCD methods, but has also developed additional design supports particularly for tackling the incompatibility between products' demands and users' capabilities. The capability-demand approach is one example of this.

In this approach, population-based capability data is used to assess design exclusion. The demands that a product makes on various user capabilities are identified, as in the example in Figure 3. These are 
then compared with data about the population to estimate how many people do not have sufficient capabilities to meet these demands, and thus would be unable to use the product (Goodman-Deane et al., 2011).

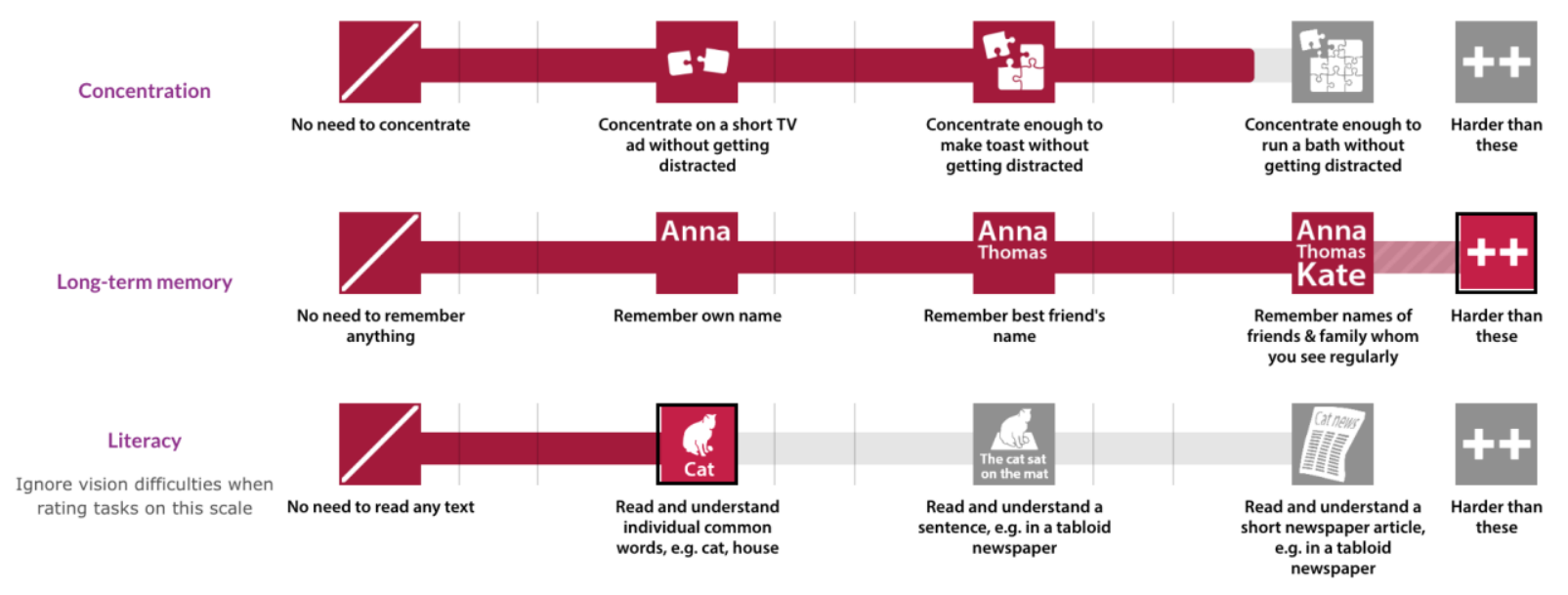

Figure 3. Some of the cognitive scales in the Exclusion Calculator (EDC, 2018)

Figure 3 shows an example of evaluating the microwave interface in Figure 1 using the Exclusion Calculator developed by the University of Cambridge (EDC, 2018). The figure shows some of the cognitive scales in the calculator - other scales can be used to assess sensory, motor and communication demands. The microwave interface places a high demand on users' memory because users need to remember multiple sequences of actions needed to achieve different goals. The demand on literacy is lower, as users only need to be able to 'read and understand individual common words'. The ratings on each scale are then compared with UK population capability data to estimate exclusion. Such a data-supported tool provides a faster and more objective way to evaluate design (Langdon and Thimbleby, 2010). However, one concern is the lack of comprehensive and up-to-date datasets to support this approach, especially for cognitive capability. There have been a number of studies initiated to collect users' cognitive capability data and to apply it in design. For example, the Exclusion Calculator uses data on users' concentration, long-term memory, literacy, speech comprehension, and speaking. Tarpin-Bernard and Habieb-Mammar (2005) proposed a framework in which users' cognitive capability was composed of memory, attention, executive function, language, and visual and spatial abilities. In a pilot UK national survey, learning and memory, executive function, and literacy and numeracy were considered to be critical capabilities in using interactive products (Tenneti et al., 2013).

For data on cognitive capability to be effective in design, it is important to clarify (a) which cognitive abilities affect people's product performance, and (b) the relationships between cognitive abilities and product features. The range of cognitive capabilities in the aforesaid studies are mainly borrowed from cognitive psychology, and little research has been carried out to clarify the relation between cognitive aspects of products and users' corresponding abilities. Therefore, it is still challenging to apply current cognitive capability data in design.

\subsection{Cognitive walkthrough}

Cognitive walkthrough is a usability inspection method. Compared with other usability methods that designers are familiar with (e.g. heuristics evaluation and usability testing), cognitive walkthrough pays particular attention to the cognitive aspects of users' experience. It focuses on the cognitive activities of users, especially on their goals and knowledge when performing a specific task (Mahatody et al., 2010). Particular attention is paid to the ease of learning to use a product (Wilson, 2014).

Cognitive walkthrough is designed for product developers so that they are able to articulate assumptions about user knowledge and thought processes. The task is presented step by step; the team is asked to craft a credible story explaining why the expected users would choose the correct action at each step. If a credible story cannot be told, then suggestions for fixing the problem are noted (Fichter, 2004). Take for example the task of 'heating a cup of milk' in the microwave in Figure 1. One of the steps in doing this is to set the power level. Designers may identify that this step can be quite 
confusing for an older person who is used to simple power and timer operations. It can be difficult to decide which is the correct action needed to set the power level. This indicates that the interface could be improved by grouping related buttons to form more easily identifiable functions.

The cognitive walkthrough method is relatively easy and quick to carry out. It can be applied flexibly during different stages of design. In particular, it is helpful in identifying low-hanging fruit, i.e. problems that can easily be remedied prior to usability testing. However, there are limits while using this method (John and Packer, 1995; Wilson, 2014):

- Designers (evaluators) must understand the intended users well as they are required to 'think in a user's thinking'. However, designers tend to assume that users have similar abilities to themselves. As a result, using cognitive walkthrough may be prone to producing biased results;

- Cognitive walkthrough is helpful in detecting problems, but it does not explicitly give solutions;

- Cognitive walkthrough does not identify the frequency or severity of problems. Therefore, designers may have difficulties in setting priorities when resolving them.

\subsection{Cognitive modelling}

Applying design principles or cognitive walkthrough are relatively easy, but with the increasing complexity of technical systems, relying on those methods is no longer adequate to address usability challenges ( $\mathrm{Li}$ and Gunal, 2012). Cognitive modelling is one way to cope with such complexities.

From a psychological perspective, cognitive modelling is an approach taken by psychologists in which models of human behaviour are developed to explain or engineer systems involving human components (Butterfield and Ngondi, 2016). In a human-product interaction context, a cognitive model can be understood as a high fidelity 'virtual user' who can perform specific tasks with the surrounding artefacts in selected environments (Li and Gunal, 2012). For instance, Cogtool (John et al., 2004) is a simple cognitive modelling tool based on the ACT-R architecture (Anderson et al., 2004). Modelers need to input the task sequence and regulate the interactive actions between each step. This model then produces an estimate of task execution time, enabling the comparison of different tasks for overall complexity of a product.

Cognitive models are efficient simulation instruments in predicting users' task performance and enable the evaluation of design to start as soon as conceptual alternatives are formalised (Ritter et al., 2001; Li and Gunal, 2012). Existing cognitive models have typically addressed people's behaviour at one of two levels of abstraction (Salvucci and Lee, 2003):

1. Higher-level modelling frameworks such as Goals-Operators-Methods-Selection (GOMS) Rules (Card et al., 1983) and its variants which represent behaviour as basic user actions such as moving a mouse or pressing a key;

2. Lower-level cognitive architectures that describe 'atomic components' of behaviour. This usually includes models developed within cognitive architectures that comprise condition-action rules that gather perceptual knowledge, perform cognitive functions, and issue motor commands. For instance, models based on Adaptive Control of Thought-Rational (ACT-R) and Symbolic Cognitive Architecture (Laird et al., 1987) fall into this level.

The benefits of using cognitive models are easily perceivable, yet design professionals from the industry still largely ignore their applications (Chittaro and De Marco, 2004; Li and Gunal, 2012). The possible reasons can be generalized as follows:

- They require a high level of expertise - modelling cognitive behaviours requires expertise in cognitive psychology, neuropsychology, intelligence and mathematics (Salvucci and Lee, 2003; Tarpin-Bernard and Habieb-Mammar, 2005);

- They are time-consuming - building detailed models for novel interfaces requires plenty of time (West and Emond, 2002; Chittaro and De Marco, 2004);

- They are not integrated into the design process - guidelines or methodologies currently do not exist to integrate cognitive models into design, as they are currently mainly used for validating hypotheses of human cognition processing instead of practical design usage ( $\mathrm{Li}$ and Gunal, 2012);

- $\quad$ They do not adequately consider individual differences - existing cognitive models tend to model an 'average person'. This is useful for comparing different versions of an interface, but weak when used to give judgement on the overall quality of an interface (Olson and Olson, 2003). Models such as ACT-R can theoretically simulate individual differences in cognitive capabilities by adjusting parameters of the model (Wong et al., 2010), but this calls for validations based on large amounts of empirical studies. 
Despite these problems, cognitive modelling can still act as a useful approach in addressing cognitive challenges in design. From a more pragmatic perspective, cognitive models are not expected to generate perfect quantitative predictions of human performance, but are helpful in identifying qualitative usability differences between interfaces.

\section{DISCUSSION}

\subsection{The insufficient uptake of cognitive design approaches by designers}

This literature review identified four approaches that can be employed to address cognitive challenges in design. However, industry practitioners have not widely adopted these approaches, especially those come from areas outside design such as cognitive modelling (West and Emond, 2002; Chittaro and De Marco, 2004).

One fundamental reason for this might lie in designers' habitual ways of evaluating designs. Designers in practice tend to consider the user's experience as a whole, which may lead to not considering cognitive aspects explicitly enough. Consequently, potential cognitive challenges can still occur even when some HCD methods have been applied in the design and evaluation process. Moreover, at an organizational level, mitigating such challenges is often considered to be the duty of usability experts instead of designers, resulting in less consideration of users' cognition in the design process.

Another cause can be the communication difficulties between cognitive research and design. Design and cognition are two fields where the boundaries of knowledge keep expanding but rarely intersect. On one hand, research into cognition integrates multiple disciplines, but it is believed that 'there is not as much application of theories, models, and specific findings from basic cognitive research to user interface design as one would hope' (Czerwinski and Larson, 2002). It is fundamentally difficult to acquire expertise in a field that is outside ones' own scope of knowledge: the time required to read the literature outside one's field can be hard to find, and the additional investment to learn novel methods from another field can be huge (Thagard, 2017). The interdisciplinary nature of cognition research implies that it can even be difficult to merge all the relevant knowledge areas as 'several disciplines are engaged in the research and application, but few people are exposed to more than one' (Grudin, 2012).

On the other hand, human-centred design skills such as observational techniques and task analysis are little represented in most cognitive science curricula (Czerwinski and Larson, 2002). Most current cognitive approaches are developed by cognitive experts and applying them in design calls for background knowledge derived from the wide-ranging fields of cognition. For instance, Mayer and Moreno (2002) proposed the Principles of Instructional Design for facilitating computer-based task learning, including: (a) the multiple presentation principle, (b) the contiguity principle, (c) the individual differences principle, and (d) the chunking principle. Implementing these principles requires designers to become familiar with jargon such as 'chunk' and 'schema', as well as the nature of individual differences within a cognitive psychology scope. Such demands on time and learning are likely to deter designers from using these principles in practice.

In addition, cognitive design methods have become increasingly more sophisticated and less accessible to practitioners (O'Hare et al., 2014). More efforts have been made to develop new design supports yet little attention has been paid to improving the usability and usefulness of these tools and methods. This can be seen in the development of cognitive modelling. Numerous cognitive models have been built either based on existing paradigms or newly-established cognitive architectures, but there are still few off-the-shelf models that be easily used by designers. Cognitive interfaces remain a challenge for designers (Peacock and Resnick, 2011).

\subsection{Addressing designers' needs and preferences}

The development of successful design supports must begin with the study of the target users and their tasks (Rosson et al., 1987). From a knowledge conversion perspective, the purpose of knowledge transfer will be lost if knowledge is transferred from source to the receiver without contextualising the way it will be used (Liyanage et al., 2009). There is a considerable body of valuable knowledge regarding cognition that designers could possibly pull from, but the theories and methods have to be made more practical and design oriented to really provide a strong cognitive foundation in design practice. 
Designers have their own 'designerly ways' of accessing information and using design supports. For example, it has been found that simple, intuitive and highly visual design supports are more appreciated by designers (McGinley and Dong, 2015), while being interactive is also desirable (Nickpour and Dong, 2015). However, design research has focused too heavily on developing tools and methods, without considering how they fit with the ways in which designers think and work (Mieczakowski et al., 2012). Insufficient attention has been paid to the validity, thoroughness, reliability, effectiveness and the ease of use of these supports, leading to tools and methods that are not being used in industry (Blessing and Chakrabarti, 2009). The consensus is that most methods proposed by researchers and scholars are not applied in professional design practice because they do not acknowledge real-world contexts and lack applicability (Schønheyder and Nordby, 2018).

A particular concern for cognitive aspects of design is that it is still unknown how designers currently work with users' cognition and take it account into design. There is also a lack of evidence clarifying how effective currently available approaches are in dealing with cognitive challenges in the real world. Further research is needed to understand how designers think about and communicate cognitive issues so as to lay the foundation for transferring knowledge to and developing design supports for designers.

\section{CONCLUSION AND FUTURE WORK}

This literature review has explored the approaches to addressing cognitive challenges in design. Instead of providing a complete list of contributions on addressing cognitive issues from the wider field of cognition, it has focused on approaches that have been applied in the design and evaluation of human-product interaction. Four approaches were selected and discussed, including cognitive design principles/guidelines, the capability-demand approach that originated in inclusive design, cognitive walkthrough and cognitive modelling. Each approach has its own merits and challenges when used in design practice.

It was found that these approaches are in fact not widely implemented by designers. The possible causes are thought to be (a) designers' habitual practices in dealing with such usability issues, (b) the communication barriers between the disciplines of design and cognition, and (c) the poor match of these approaches to designers' normal ways of designing, causing difficulties with the usability of current approaches.

Based on the conclusions drawn so far, two approaches for future development of design supports seem promising. One approach is to improve current supports so that they better match designers' way of working. In particular, they should be tailored to the characteristics of different design disciplines. For instance, design supports for the development of mobile applications should fit the fast and iterative process typically in this discipline. Another approach is to develop new supports based on designers' needs. For example, despite the fact that there are numerous design guidelines 'readily available', designers from industry still tend to form their own sets of guidelines based on their experience (Oygür, 2017). In view of this, it has been suggested that design patterns may be a better approach than new guidelines (Van Biljon and Renaud, 2016). A design pattern is a general repeatable solution to a common design problem, based on existing good practice. To address these issues, interviews and field observation will be carried out to better understand how designers currently think about and design for users' cognition in practice and to identify their preferences for how cognitive design supports.

\section{REFERENCES}

Abascal, J. and Nicolle, C. (2005), "Moving towards inclusive design guidelines for socially and ethically aware HCI", Interacting with Computers, Vol. 17 No. 5, pp. 484-505. http://dx.doi.org/10.1016/j.intcom.2005.03.002.

Altay, B. (2017), "Multisensory Inclusive Design Education: A 3D Experience", The Design Journal, Vol. 20 No. 6, pp. 821-846. http://dx.doi.org/10.1080/14606925.2017.1371949.

Anderson, J.R., Bothell, D., Byrne, M.D., Douglass, S., Lebiere, C. and Qin, Y. (2004), “An integrated theory of the mind”, Psychological review, Vol. 111 No. 4, p. 1036. http://dx.doi.org/10.1037/0033-295X.111.4.1036.

Bastien, J.M.C. and Scapin, D.L. (1992), “A validation of ergonomic criteria for the evaluation of human-computer interfaces", International Journal of Human-Computer Interaction, Vol. 4 No. 2, pp. 183-196. http://dx.doi.org/10.1080/10447319209526035.

Bastien, J.M.C. and Scapin, D.L. (1995), "How usable are usability principles, criteria and standards?" in: Advances in Human Factors/Ergonomics Elsevier, pp. 343-348.https://doi.org/10.1016/S0921-2647(06)80240-6 
Blair-Early, A. and Zender, M. (2008), "User interface design principles for interaction design”, Design Issues, Vol. 24 No. 3, pp. 85-107. http://dx.doi.org/10.1162/desi.2008.24.3.85.

Blessing, L.T. and Chakrabarti, A. (2009), DRM, a design research methodology, Springer Science \& Business Media. https://doi.org/10.1007/978-1-84882-587-1_2

BSI (2005), BS 7000-6:2005 Design management systems, British Standards Institute, Lodon

Butterfield, A. and Ngondi, G.E. (2016), A dictionary of computer science, Seventh ed., Oxford University Press. http://dx.doi.org/10.1093/acref/9780199688975.001.0001

Card, S.K., Newell, A. and Moran, T.P. (1983), The Psychology of Human-Computer Interaction, L. Erlbaum Associates Inc. https://doi.org/10.1201\%2F9780203736166

Chittaro, L. and De Marco, L. (2004), "Driver distraction caused by mobile devices: studying and reducing safety risks", in 1st Int'l workshop mobile technologies and health: Benefits and Risks, pp. 1-19.

Clarkson, P.J., Waller, S. and Cardoso, C. (2015), “Approaches to estimating user exclusion”, Applied Ergonomics, Vol. 46 Part B, pp. 304-310. http://dx.doi.org/10.1016/j.apergo.2013.03.001.

Czerwinski, M.P. and Larson, K. (2002), "Cognition and the Web: moving from theory to Web design" in: Ratner, J., (ed). Human Factors and Web Development, Second ed., Erlbaum, Boca Raton, NJ. http://dx.doi.org/10.1201/b12467

Darses, F. and Wolff, M. (2006), "How do designers represent to themselves the users' needs?", Applied Ergonomics, Vol. 37 No. 6, pp. 757-764. http://dx.doi.org/10.1016/j.apergo.2005.11.004.

EDC (2018), Exclusion Calculator Inclusive Design Toolkit, available: http://calc.inclusivedesigntoolkit.com/ [accessed 19 July].

Fichter, D. (2004), "Heuristic and cognitive walk-through evaluations", Online, Vol. 28 No. 3, pp. 53-56.

Frøkjær, E. and Hornbæk, K. (2008), "Metaphors of human thinking for usability inspection and design", $A C M$ Transactions on Computer-Human Interaction (TOCHI), Vol. 14 No. 4, p. 20. http://dx.doi.org//10.1145\%2F1314683.1314688.

Gersh, J.R., McKneely, J.A. and Remington, R.W. (2005), “Cognitive engineering: Understanding human interaction with complex systems”, Johns Hopkins APL technical digest, Vol. 26 No. 4, pp. 377-382.

Goodman-Deane, J., Waller, S.D., Williams, E.Y., Langdon, P.M. and Clarkson, P.J. (2011), "Estimating exclusion: a tool to help designers", in Include 2011, London, 18-20 April 2011, Royal College of Art.

Grudin, J. (2012), “A Moving Target: The Evolution of Human-Computer Interaction Introduction” in: Jacko, J. A., (ed). Human-Computer Interaction Handbook: Fundamentals, Evolving Technologies, and Emerging Applications, Third ed. CRC Press pp. xxvii-lxi

John, B.E. and Packer, H. (1995), "Learning and using the cognitive walkthrough method: a case study approach", in Proceedings of the SIGCHI conference on Human factors in computing systems, ACM Press/Addison-Wesley Publishing Co., pp. 429-436, available: http://dx.doi.org//10.1145/223904.223962.

John, B.E., Prevas, K., Salvucci, D.D. and Koedinger, K. (2004), "Predictive human performance modeling made easy", in Proceedings of the SIGCHI conference on Human factors in computing systems, ACM, pp. 455-462, available: http://dx.doi.org/10.1145/985692.985750.

Johnson, J. (2013), Designing with the mind in mind: simple guide to understanding user interface design guidelines, Elsevier. https://doi.org/10.1016/B978-0-12-407914-4.00001-4

Kalyuga, S., Plass, J.L., Moreno, R. and Brunken, R. (2010), "Schema Acquisition and Sources of Cognitive Load" in: Plass, J. L., Brünken, R. and Moreno, R., eds., Cognitive Load Theory, Cambridge University Press, Cambridge, pp. 48-64. http://dx.doi.org/10.1017/cbo9780511844744.005

Laird, J.E., Newell, A. and Rosenbloom, P.S. (1987), "Soar: An architecture for general intelligence", Artificial intelligence, Vol. 33 No. 1, pp. 1-64. http://dx.doi.org//10.1016/0004-3702(87)90050-6.

Langdon, P. and Thimbleby, H. (2010), "Inclusion and interaction: Designing interaction for inclusive populations", Interacting with Computers, Vol. 22 No. 6, pp. 439-448. http://dx.doi.org/10.1016/j.intcom.2010.08.007.

Li, X.Y. and Gunal, M. (2012), "Exploring cognitive modelling in engineering usability design", Journal of Engineering Design, Vol. 23 No. 1-3, pp. 77-97. http://dx.doi.org/10.1080/09544828.2010.528379.

Liyanage, C., Elhag, T., Ballal, T. and Li, Q. (2009), "Knowledge communication and translation-a knowledge transfer model”, Journal of Knowledge management, Vol. 13 No. 3, pp. 118-131. http://dx.doi.org//10.1108/13673270910962914.

Maguire, M. (2001), "Methods to support human-centred design”, International Journal of Human-Computer Studies, Vol. 55 No. 4, pp. 587-634. http://dx.doi.org//10.1006/ijhc.2001.0503.

Mahatody, T., Sagar, M. and Kolski, C. (2010), "State of the Art on the Cognitive Walkthrough Method, Its Variants and Evolutions”, International Journal of Human-Computer Interaction, Vol. 26 No. 8, pp. 741-785. http://dx.doi.org/92478501210.1080/10447311003781409.

Mayer, R.E. and Moreno, R. (2002), “Aids to computer-based multimedia learning”, Learning and Instruction, Vol. 12 No. 1, pp. 107-119. http://dx.doi.org/10.1016/S0959-4752(01)00018-4.

McGinley, C. and Dong, H. (2015), "Designing with Information and Empathy: Delivering Human Information to Designers", The Design Journal, Vol. 14 No. 2, pp. 187-206.

http://dx.doi.org/10.2752/175630611x12984592780005. 
Mieczakowski, A., Langdon, P. and Clarkson, P.J. (2012), “Investigating designers' and users' cognitive representations of products to assist inclusive interaction design", Universal Access in the Information Society, Vol. 12 No. 3, pp. 279-296. http://dx.doi.org/10.1007/s10209-012-0278-8.

Nickpour, F. and Dong, H. (2015), "Designing Anthropometrics! Requirements Capture for Physical Ergonomic Data for Designers", The Design Journal, Vol. 14 No. 1, pp. 92-111. http://dx.doi.org/10.2752/175630610x12877385838849.

O’Hare, D., Wiggins, M., Williams, A. and Wong, W. (2014), “Cognitive task analyses for decision centred design and training" in: Task analysis, CRC Press, pp. 176-196

Olson, G.M. and Olson, J.S. (2003), "Human-computer interaction: Psychological aspects of the human use of computing”, Annual review of psychology, Vol. 54 No. 1, pp. 491-516. http://dx.doi.org/10.1146/annurev.psych.54.101601.145044.

Oygür, I. (2017), "User, Research, and Practice. Learning from Design Consultancies”, The Design Journal, Vol. 20 No. sup1, pp. S4621-S4631. http://dx.doi.org/10.1080/14606925.2017.1352959.

Peacock, B. and Resnick, M. (2011), "The Six Us: An Ergonomics Approach to Enhancing Product and Process Evaluations”, Ergonomics in Design, Vol. 19 No. 2, pp. 25-29. http://dx.doi.org/10.1177/1064804611408016.

Ritter, F.E., Baxter, G.D., Jones, G. and Young, R.M. (2001), "User interface evaluation: How cognitive models can help" in: Carroll, J. M., (ed). Hu6man-computer interaction in the new millennium, pp. 125-147. https://doi.org/10.1145/638574.638592

Rosson, M.B., Maass, S. and Kellogg, W.A. (1987), "Designing for designers: an analysis of design practice in the real world”, in CHI '87 Proceedings of the SIGCHI/GI Conference on Human Factors in Computing Systems and Graphics Interface, Toronto, Ontario, Canada http://dx.doi.org/10.1145/29933.30873, ACM, pp. 137-142 available: http://dx.doi.org/10.1145/29933.30873.

Salvucci, D.D. and Lee, F.J. (2003), "Simple cognitive modeling in a complex cognitive architecture", in Proceedings of the SIGCHI conference on Human factors in computing systems, ACM, pp. 265-272, available: http://dx.doi.org//10.1145/642611.642658

Schønheyder, J.F. and Nordby, K. (2018), "The use and evolution of design methods in professional design practice", Design Studies, Vol. 58, pp. 36-62. http://dx.doi.org//10.1016/j.destud.2018.04.001.

Shankar, A., Lin, H., Brown, H.-F. and Rice, C. (2015), "Rapid Usability Assessment of an Enterprise Application in an Agile Environment with CogTool", in Proceedings of the 33rd Annual ACM Conference Extended Abstracts on Human Factors in Computing Systems, ACM, Seoul, Republic of Korea, pp. 719-726, available: http://dx.doi.org//10.1145/2702613.2702960.

Tarpin-Bernard, F. and Habieb-Mammar, H. (2005), "Modeling elementary cognitive abilities for adaptive hypermedia presentation", User Modeling and User-Adapted Interaction, Vol. 15 No. 5, pp. 459-495. http://dx.doi.org/10.1007/s11257-005-2529-3.

Tenneti, R., Goodman-Deane, J., Langdon, P., Waller, S., Ruggeri, K., Clarkson, P.J. and Huppert, F.A. (2013), "Design and delivery of a national pilot survey of capabilities", International Journal of Human Factors and Ergonomics, Vol. 2 No. 4, pp. 281-305. http://dx.doi.org//10.1504/ijhfe.2013.059375

Thagard, P. (2017), "Cognitive Science” in: Frodeman, R., (ed). The Oxford Handbook of Interdisciplinarity, 2 ed. Oxford University Press. http://dx.doi.org/10.1093/oxfordhb/9780198733522.001.0001

Van Biljon, J. and Renaud, K. (2016), "Validating mobile phone design guidelines: Focusing on the elderly in a developing country", in Proceedings of the Annual Conference of the South African Institute of Computer Scientists and Information Technologists, ACM, p. 44.

West, R.L. and Emond, B. (2002), "Can cognitive modeling improve rapid prototyping”, in Erik M. Altmann, A. C., Christian D. Schunn, Wayne D. Gray, ed., Proceedings of the Fourth International Conference on Cognitive Modeling, New York, pp. 271-273, available: http://dx.doi.org//10.4324/9781410605979

Wilson, C. (2014), “Cognitive Walkthrough” in: Wilson, C., (ed). User Interface Inspection Methods, Morgan Kaufmann, Boston, pp. 65-79. http://dx.doi.org/10.1016/b978-0-12-410391-7.00004-x

Wong, T.J., Cokely, E.T. and Schooler, L.J. (2010), “An online database of ACT-R parameters: Towards a transparent community-based approach to model development", in Proceedings of the 10th international conference on cognitive modeling, Citeseer, pp. 282-286.

Zaphiris, P., Kurniawan, S. and Ghiawadwala, M. (2006), "A systematic approach to the development of researchbased web design guidelines for older people", Universal Access in the Information Society, Vol. 6 No. 1, pp. 59-75. http://dx.doi.org/10.1007/s10209-006-0054-8.

\section{ACKNOWLEDGMENTS}

This study is funded by Trinity Hall Research Studentship. The authors would like to thank Dr Patrick Langdon who has provided valuable and constructive suggestions during the planning and development of this research work. 